\title{
Development and Evaluation of Gastroretentive Floating Tablets of an Antihypertensive Drug Using Hydrogenated Cottonseed Oil
}

\author{
Harshal Ashok Pawar, ${ }^{1}$ Pooja Ramchandra Gharat, ${ }^{1}$ Rachana Vivek Dhavale, \\ Pooja Rasiklal Joshi, ${ }^{1}$ and Pushpita Pankajkumar Rakshit ${ }^{2}$ \\ ${ }^{1}$ Dr. L. H. Hiranandani College of Pharmacy, Smt. CHM Campus, Opp. Ulhasnagar Railway Station, \\ Ulhasnagar, Maharashtra 421003, India \\ ${ }^{2}$ SVKM'S NMIMS, Vile Parle (W), Mumbai, Maharashtra 400056, India
}

Correspondence should be addressed to Harshal Ashok Pawar; harshal.dlhhcop@gmail.com

Received 30 September 2013; Accepted 7 November 2013

Academic Editors: O. A. Odeku and R. Zelkó

Copyright ( 2013 Harshal Ashok Pawar et al. This is an open access article distributed under the Creative Commons Attribution License, which permits unrestricted use, distribution, and reproduction in any medium, provided the original work is properly cited.

\begin{abstract}
The aim of the present work was to develop a gastroretentive floating tablet of Atenolol and investigate the effects of both hydrophilic and hydrophobic retardant on in vitro release. Atenolol is an antihypertensive drug with an oral bioavailability of only $50 \%$ because of its poor absorption from lower gastrointestinal tract. The floating tablets of Atenolol were prepared to increase the gastric retention, to extend the drug release, and to improve the bioavailability of the drug. The floating tablets were formulated using hydrophilic polymers as Hydroxy propyl methyl cellulose (HPMC K4M and HPMC K15M), hydrophobic retardant as a hydrogenated cottonseed oil (HCSO), and sodium bicarbonate as a gas generating agent to reduce floating lag time. The formulated tablets were evaluated for the quality control tests such as weight variation, hardness, friability, swelling index, floating lag time, and total floating time. The in vitro release study of the tablets was performed in $0.1 \mathrm{~N} \mathrm{HCl}$ as a dissolution media. The results of the present study clearly indicates the promising potential of Atenolol floating system as an alternative to the conventional dosage and other sustained release formulations. The study also revealed the effectiveness of HCSO as retardant in combination with HPMC.
\end{abstract}

\section{Introduction}

The oral bioavailability of many drugs is limited by their unfavourable physicochemical characteristics or absorption in well-defined part of the gastrointestinal tract (GIT) referred as "absorption window" [1]. Prolonged gastric retention improves bioavailability, reduces drug waste, and improves the solubility for drugs that are less soluble in a high $\mathrm{pH}$ environment [2]. Various approaches have been investigated to increase the retention of oral dosage form in the stomach, including floating systems, swelling and expanding systems, bioadhesive systems, modified shape systems, high density systems, and other delayed gastric emptying devices [1].

Atenolol is a beta (1)-adrenergic antagonist or more commonly known as a beta-blocker used in the treatment of hypertension and angina pectoris. Chemical name of Atenolol is 4-[2-hydroxy-3-[(1-methyl ethyl)amino]propoxy] benzene acetamide. Molecular structure of Atenolol is as shown Figure 1.

Atenolol undergoes little or no hepatic first pass metabolism and its elimination half-life is 6 to 7 hours. The present modes of administration of Atenolol are oral and Parenteral. It is incompletely absorbed from the gastrointestinal tract and has an oral bioavailability of only $50 \%$, while the remaining is excreted unchanged in faeces. Therefore, it is selected as a suitable drug for the design of a gastroretentive floating drug delivery system (GFDDS) with a view to improve its oral bioavailability.

Hydroxy propyl methyl cellulose (HPMC) is hydrophilic cellulose ether widely used as release retarding material. HPMC releases drug by diffusion mechanism. HCSO belongs 


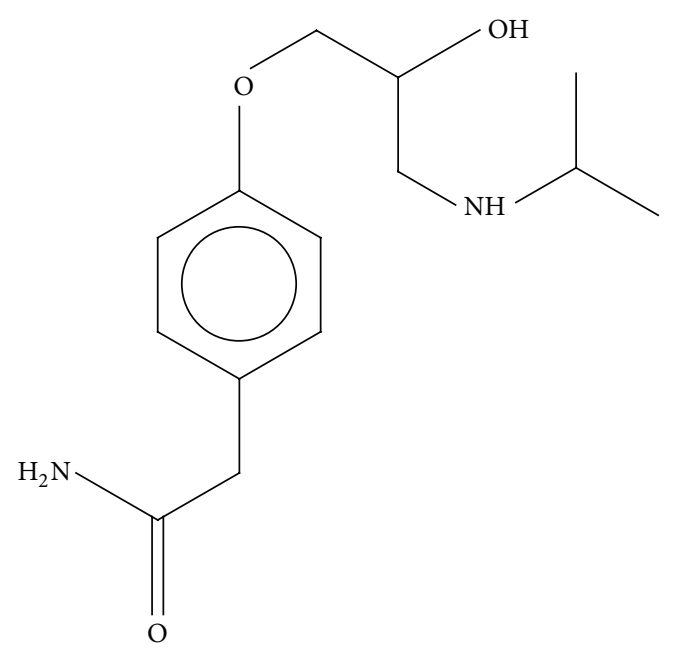

FIgURE 1: Structure of Atenolol.

to USP-NF type 1 consisting of triglycerides of hydroxy stearic acid widely used as a tablet lubricant [3]. In the present study, HCSO was investigated as hydrophobic matrix forming retardant as well as floating material.

The objective of the present study was to develop a gastroretentive floating drug delivery system (GFDDS) of Atenolol and to examine the effects of both hydrophilic and hydrophobic retardant on in vitro drug release. In the present study, Atenolol floating tablets were prepared by using hydrophilic polymer, HPMC K4M, HPMC K15M, and HCSO as a hydrophobic retardant, alone and in combination to study the release kinetics and find out the effects of both the retardants and their combinations.

\section{Materials and Methods}

2.1. Materials. Atenolol was obtained as a gift sample from Kopran Pvt. Ltd., Mumbai. HPMC K4M and HPMC K15M were supplied by Colorcon Pvt. Ltd., Goa. Hydrogenated cottonseed oil was obtained as a gift sample from Lubritab, New York. All other chemicals and reagent used were of analytical grade.

2.2. Drug Excipients Compatibility Study. Compatibility studies were carried out to know the possible interactions between Atenolol and excipients used in the formulation. Physical mixtures of drug and excipients in the ratio 1:1 were prepared to study the compatibility. Drug polymer compatibility studies were carried out using FTIR spectroscopy. The IR spectra's were recorded in between $500-4000 \mathrm{~cm}^{-1}$.

2.3. Preparation of Tablets. Floating tablets containing Atenolol were prepared by direct compression technique using varying concentrations of retardants (HPMC and HCSO) with sodium bicarbonate. All the powders were accurately weighed and passed through 40 mesh sieve. Then, except Magnesium stearate all other ingredients were mixed thoroughly for 15 minutes. After sufficient mixing of
TABLE 1: (a) Composition of gastroretentive floating tablets of Atenolol prepared using hydrophobic retardant (HCSO) (F1 to F4). (b) Composition of gastroretentive floating tablets of Atenolol prepared using hydrophilic polymer (HPMC K4M) (F5 to F8). (c) Composition of gastroretentive floating tablets of Atenolol prepared using hydrophilic polymer (HPMC K15M) (F9 to F12). (d) Composition of gastroretentive floating tablets of Atenolol prepared using hydrophilic-hydrophobic combination (F13 to F18).

(a)

\begin{tabular}{lccccc}
\hline S. No & Ingredients & F1 & F2 & F3 & F4 \\
\hline 1 & Atenolol & 50 & 50 & 50 & 50 \\
2 & Hydrogenated cottonseed oil & 50 & 100 & 150 & 175 \\
3 & Sodium bicarbonate & 45 & 45 & 45 & 45 \\
4 & Avicel & 152 & 102 & 52 & 27 \\
5 & Magnesium stearate & 3 & 3 & 3 & 3 \\
\hline
\end{tabular}

(b)

\begin{tabular}{lccccc}
\hline S. No & Ingredients & F5 & F6 & F7 & F8 \\
\hline 1 & Atenolol & 50 & 50 & 50 & 50 \\
2 & HPMC K4M & 50 & 100 & 150 & 175 \\
3 & Sodium bicarbonate & 45 & 45 & 45 & 45 \\
4 & Avicel & 152 & 102 & 52 & 27 \\
5 & Magnesium stearate & 3 & 3 & 3 & 3 \\
\hline
\end{tabular}

(c)

\begin{tabular}{lccccc}
\hline S. No & Ingredients & F9 & F10 & F11 & F12 \\
\hline 1 & Atenolol & 50 & 50 & 50 & 50 \\
2 & HPMC K15M & 50 & 100 & 150 & 175 \\
3 & Sodium bicarbonate & 45 & 45 & 45 & 45 \\
4 & Avicel & 152 & 102 & 52 & 27 \\
5 & Magnesium stearate & 3 & 3 & 3 & 3 \\
\hline
\end{tabular}

(d)

\begin{tabular}{lccccccc}
\hline S. No & Ingredients & F13 & F14 & F15 & F16 & F17 & F18 \\
\hline 1 & Atenolol & 50 & 50 & 50 & 50 & 50 & 50 \\
2 & Hydrogenated & 16.67 & 33.33 & 50 & 25 & 70 & 15 \\
& cottonseed oil & & & & & & \\
3 & HPMC K4M & 16.67 & 33.33 & 25 & 50 & 15 & 70 \\
4 & HPMC K15M & 16.67 & 33.33 & 25 & 25 & 15 & 15 \\
5 & Sodium bicarbonate & 45 & 45 & 45 & 45 & 45 & 45 \\
6 & Avicel & 152 & 102 & 102 & 102 & 102 & 102 \\
7 & Magnesium stearate & 3 & 3 & 3 & 3 & 3 & 3 \\
\hline
\end{tabular}

drug as well as other components, Magnesium stearate was added, as post lubricant, and the blend was further mixed for additional 2-3 minutes. The final blend was compressed into tablets having average weight of $300 \mathrm{mg}$ using a single punch tablet machine (Royal Artist, India) fitted with an $10 \mathrm{~mm}$ round flat punches. The compositions of all formulations are given in Table 1.

\subsection{Evaluation of Tablet Properties}

2.4.1. Determination of Precompression Parameters. The preformulation studies including Bulk density, Tapped density, 
Hausner's ratio, and Angle of repose were performed of the powder [4].

2.4.2. Determination of Postcompression Parameters. Consider the following.

(1) Hardness Test. Monsanto hardness tester was used for the determination of hardness of tablets [5].

(2) Friability. Twenty tablets were accurately weighed and placed in the friabilator (Roche's Friabilator) and operated for 100 revolutions. The tablets were dedusted and reweighed. The tablets that loose less than $1 \%$ weight were considered to be compliant [6].

The $\%$ friability was then calculated by

$$
\% \text { friability }=\frac{(\text { initial weight }- \text { final weight })}{\text { initial weight }} * 100 \text {. }
$$

(3) Weight Variation. Twenty tablets were selected randomly from the lot and weighed individually to check for weight variation [7].

(4) Drug Content (Assay). Ten tablets were finely powdered; quantities of the powder equivalent to $50 \mathrm{mg}$ of Atenolol were accurately weighed and transferred to a $100 \mathrm{~mL}$ of volumetric flask. The flask was filled with $0.1 \mathrm{~N} \mathrm{HCl}$ ( $\mathrm{pH} 1.2$ buffers) solution and mixed thoroughly. The solution was made up to volume $100 \mathrm{~mL}$ and filtered. Dilute $1 \mathrm{~mL}$ of the resulting solution to $100 \mathrm{~mL}$ with $0.1 \mathrm{~N} \mathrm{HCl}$. The absorbance of the resulting solution was measured at $226 \mathrm{~nm}$ using a Shimadzu UVvisible spectrophotometer. The linearity equation obtained from calibration curve was used for estimation of Atenolol in the tablet formulations [8].

(5) In Vitro Buoyancy Studies. The tablets were placed in a $250 \mathrm{~mL}$ beaker, containing $200 \mathrm{~mL}$ of $0.1 \mathrm{~N} \mathrm{HCl}$. The time required for the tablet to rise to the surface and float was determined as floating lag time (FLT) and the time period up to which the tablet remained buoyant is determined as total floating time (TFT) [9].

(6) Swelling Study. The tablets were weighed individually (designated as $W_{0}$ ) and placed separately in petri dish containing $5 \mathrm{~mL}$ of $0.1 \mathrm{~N} \mathrm{HCl}$ and incubated at $37^{\circ} \mathrm{C} \pm 1^{\circ} \mathrm{C}$. At regular $2 \mathrm{~h}$ time intervals until $12 \mathrm{~h}$, the tablets were removed from petri dish, and the excess surface liquid was removed carefully using the tissue paper [10]. The swollen floating tablets were then reweighed $\left(W_{t}\right)$ and \% swelling index (SI) was calculated using the following formula:

$$
\text { SI }(\%)=\left(W_{t}-\frac{W_{0}}{W_{0}}\right) \times 100 .
$$

(7) In Vitro Dissolution Studies. The in vitro dissolution of all the batches were carried out in $0.1 \mathrm{~N} \mathrm{HCl}$ as the dissolution medium using USP Type II apparatus (TDT-08L, Electrolab) apparatus at $50 \mathrm{rpm}$. The temperature was maintained at 37 $\pm 0.5^{\circ} \mathrm{C}$. The dissolution was carried out for 12 hours. The absorbances of the samples at different time intervals were carried out using UV visible spectrophotometer (UV 1800, Shimadzu) at $\lambda \max$ of $226 \mathrm{~nm}$ [11].

(8) Kinetics Study. The mechanism of Atenolol release from the floating tablets was studied by fitting the dissolution data of optimized formulation in following models:

$$
\begin{aligned}
& \text { Zero order: } M=M_{0}-K_{0} t ; \\
& \text { First order: } \log C=\log C_{0}-K t / 2.303 \text {; } \\
& \text { Higuchi square root law: } Q=k t^{1 / 2} ; \\
& \text { Korsemeyer's model: } M_{t} / M_{\infty}=k t^{n} ;
\end{aligned}
$$

where $M, C$, and $Q$ are the amount of drug released at time $t, M_{0}$, and $C_{0}$ are total amount of drug, and $K_{0}, K$, and $k$ are corresponding rate constant. In case of Korsemeyer's model $M_{t} / M_{\infty}$ is the fractional drug release at time $t, k$ is a constant incorporating the properties of the macromolecular polymeric systems and the drug, $n$ is a kinetic constant, which is used to characterize the transport mechanism. The value of $n$ for a cylinder is $<0.5$ for fickian release, $0.5<n<1.0$ for Anomalous transport (Nonfickian diffusion), 1.0 for Case-II transport, $>1.0$ for Super Case-II transport type release [12].

(9) Stability Studies. The optimized formulation of Atenolol were packed in amber color bottle and aluminum foil laminated on the upper part of the bottle and these packed formulation was stored in stability chamber maintained at $40^{\circ} \mathrm{C} \pm 2^{\circ} \mathrm{C}$ and $75 \% \pm 5 \% \mathrm{RH}$ for 3 months. The samples were withdrawn periodically and evaluated for their drug content, in vitro buoyancy studies and for in vitro drug release [13].

\section{Result and Discussion}

3.1. Drug-Excipients Compatibility Studies. The peaks obtained in the spectra of each formulation correlates with the peaks of drug spectrum. It does not show any welldefined interaction between Atenolol and excipients. This indicates that the drug is compatible with the formulation components. The spectra for pure drug, drug-excipients mixture and optimized formulation are shown in Figures 2, $3,4,5$, and 6 .

3.2. Precompression Parameters. Results of the precompression parameters performed on the blend for batch F1 to F18 are tabulated in Table 2. The bulk density and the tapped density for all the formulations varied from 0.384 to $0.486 \mathrm{~g} / \mathrm{mL}$ and 0.4809 to $0.5667 \mathrm{~g} / \mathrm{mL}$, respectively. The percentage compressibility of powder was determined using Carr's compressibility index. Carr's index lies within the range of 11.2 to $23.08 \%$. All formulations show good compressibility. Hausner ratio was found to be in the range of 1.13 to 1.22 . Angle of repose of all the formulations was found to be less than $30^{\circ}$, which indicates a good flow property of the powders.

3.3. Postcompression Parameters. The formulated tablets were subjected for post compressional evaluation such as thickness, hardness, weight variation, friability, drug content, 


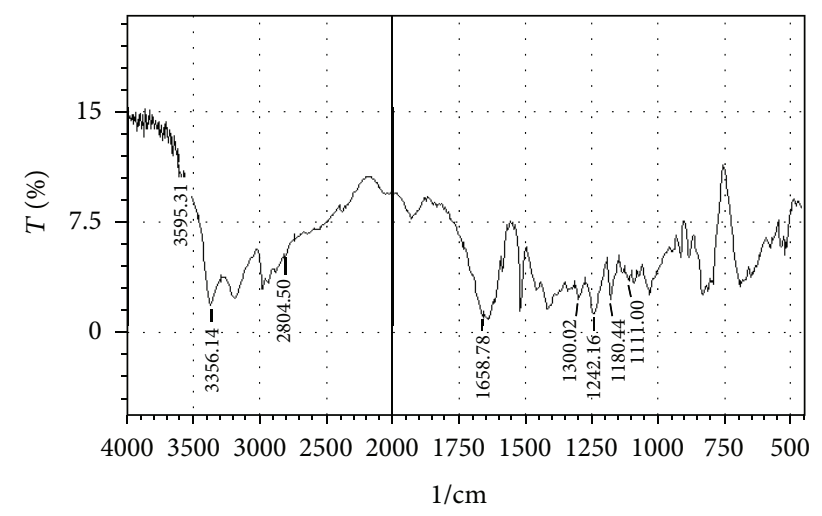

FIGURE 2: FTIR spectrum of drug (Atenolol).

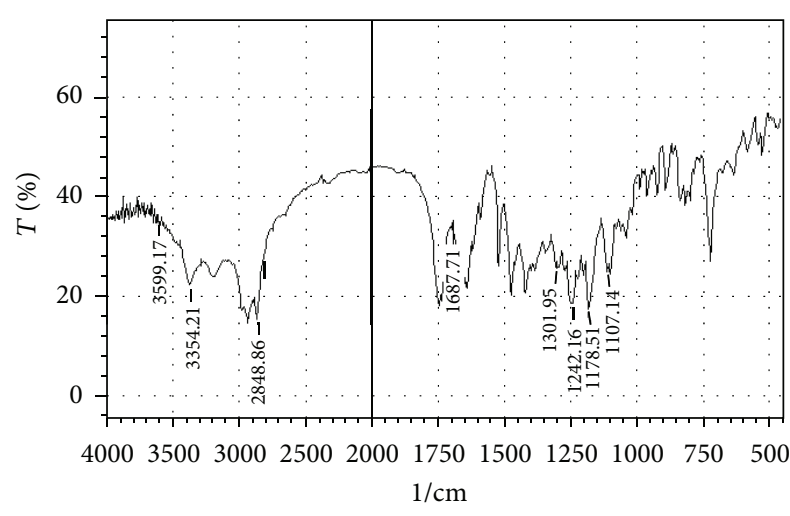

FIGURE 3: FTIR spectrum of drug with HCSO.

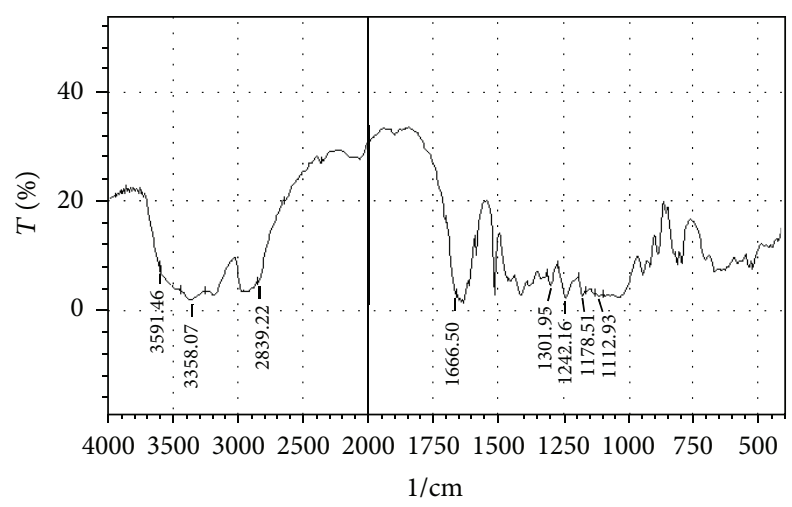

FIGURE 4: FTIR spectrum of drug with HPMC K4M.

in vitro buoyancy studies, swelling studies, in vitro dissolution studies, and stability studies. Tablet thickness $(n=3)$ was almost uniform in all the formulations and values for tablets ranged from 3.2 to $3.88 \mathrm{~mm}$. The hardness of all formulations was in the range of 8 to $12 \mathrm{~kg} / \mathrm{cm}^{2}$, indicating satisfactory mechanical strength. The weights of tablets ranged from 290 to $312 \mathrm{mg}$. All the tablets passed weight variation test as the $\%$ weight variation was within the acceptable limits of $\pm 5 \%$ of the weight as per Indian Pharmacopoeia. The friability values ranged from 0.11 to $0.49 \%$. All the values are below

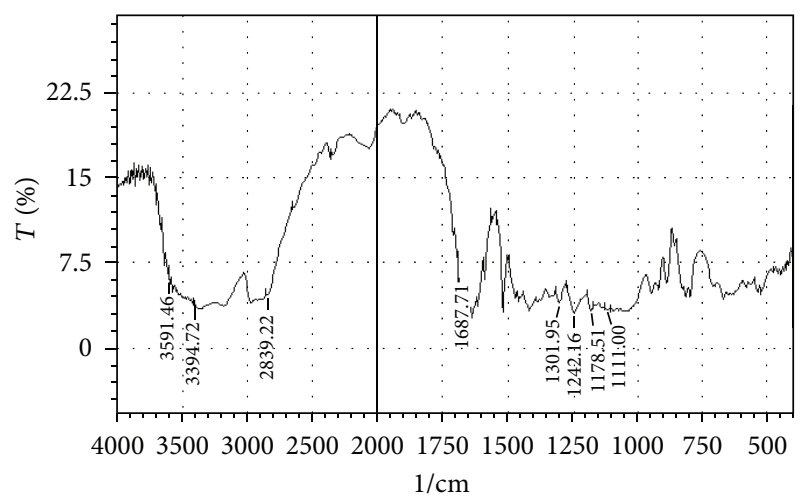

FIGURE 5: FTIR spectrum of drug with HPMC K15M.

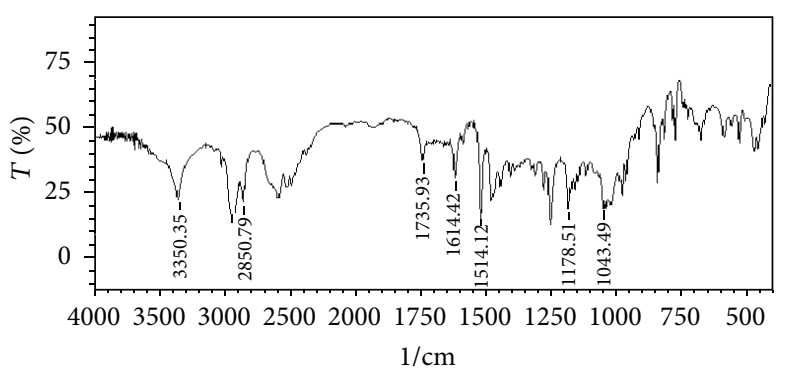

FIGURE 6: FTIR spectrum of optimized batch (F17).

$1 \%$ indicating that the tablets of all formulations are having good compactness and showing enough resistance to the mechanical shock and abrasion. The percent drug content of the tablets was found to be in between 97 to $103 \%$. Table 3 shows the results of physicochemical characters of Atenolol tablets.

3.4. In Vitro Buoyancy Studies. In vitro buoyancy of the tablets from each formulation F1 to F18 was evaluated and the results are mentioned in Table 4, where the highest and lowest floating lag time (FLT) were observed with the formulation hydrogenated cottonseed oil and HPMC, respectively.

3.5. Swelling Index. The swelling index of the tablets from each formulation F1 to F18 was evaluated and the results are mentioned in Table 5 and plot of \% swelling index versus time (hrs) is depicted in Figure 7, where the highest and lowest swelling was observed with the formulation F5 and F12 after 12 hrs, respectively. No significant swelling was observed with Formulation F1-F4 since they were prepared using HCSO. The swelling index was increased with concentration of HPMC since this polymer gradually absorbs buffer due to hydrophilic nature.

3.6. In Vitro Dissolution Studies. The in vitro drug release profiles for the formulations F1-F18 were depicted in Tables 6 and 7. The plot of cumulative percentage drug release versus time (hrs) for formulations F1-F4, F5-F8, F9-F12 and F15F17 were plotted and depicted in Figures 8, 9, 10, and 11, respectively. 
TABLE 2: Precompression parameters of designed formulations (F1-F17).

\begin{tabular}{lcccc}
\hline Formulation code & Bulk density $(\mathrm{mg} / \mathrm{mL})$ & \multicolumn{2}{c}{ Precompression evaluation parameters } \\
& $(n=3)$ Mean $\pm \mathrm{SD}$ & Tapped density $(\mathrm{mg} / \mathrm{mL})$ & Carr's index & Angle of repose \\
$(n=3)$ Mean \pm SD & $(\%)$ & $23=3)$ Mean \pm SD & Hausner's ratio \\
\hline F1 & $0.384 \pm 0.009$ & $0.5 \pm 0.010$ & 23.08 & $23.01 \pm 1.289$ \\
F2 & $0.4081 \pm 0.007$ & $0.5 \pm 0.012$ & 18.38 & $27.02 \pm 1.30$ \\
F3 & $0.4545 \pm 0.006$ & $0.52631 \pm 0.014$ & 13.64 & $22.29 \pm 0.912$ \\
F4 & $0.4166 \pm 0.010$ & $0.52631 \pm 0.011$ & 15.56 & $28.36 \pm 1.344$ \\
F5 & $0.4233 \pm 0.004$ & $0.4825 \pm 0.013$ & 12.4 & $28.1 \pm 1.23$ \\
F6 & $0.4324 \pm 0.009$ & $0.5059 \pm 0.008$ & 15.7 & $28.1 \pm 1.45$ \\
F7 & $0.4256 \pm 0.008$ & $0.4809 \pm 0.015$ & 12.8 & $27.6 \pm 0.82$ \\
F8 & $0.4065 \pm 0.011$ & $0.4837 \pm 0.011$ & 15.9 & $29.32 \pm 1.23$ \\
F9 & $0.4324 \pm 0.009$ & $0.4886 \pm 0.009$ & 12.8 & $27.6 \pm 1.66$ \\
F10 & $0.4065 \pm 0.007$ & $0.4837 \pm 0.012$ & 12.3 & $29.36 \pm 1.25$ \\
F11 & $0.4546 \pm 0.006$ & $0.5227 \pm 0.014$ & 11.2 & $28.76 \pm 1.33$ \\
F12 & $0.4166 \pm 0.009$ & $0.4915 \pm 0.012$ & 11.3 & $26.74 \pm 0.911$ \\
F13 & $0.4324 \pm 0.011$ & $0.48861 \pm 0.009$ & 12.2 & $25.3 \pm 1.155$ \\
F14 & $0.4088 \pm 0.006$ & $0.4782 \pm 0.010$ & 11.5 & 1.14 \\
F15 & $0.4632 \pm 0.005$ & $0.528 \pm 0.011$ & 14.7 & 1.17 \\
F16 & $0.4321 \pm 0.009$ & $0.4882 \pm 0.012$ & 15.7 & $28.7 \pm 0.81$ \\
F17 & $0.4776 \pm 0.007$ & $0.5667 \pm 0.014$ & 16.9 & $29 \pm 1.43$ \\
F18 & $0.486 \pm 0.005$ & $0.523 \pm 0.012$ & 11.5 & $28.67 \pm 1.33$ \\
\hline
\end{tabular}

TABLE 3: Postcompression parameters of designed formulations (F1-F18).

\begin{tabular}{|c|c|c|c|c|c|}
\hline \multirow[b]{2}{*}{ Formulation code } & \multicolumn{5}{|c|}{ Postcompression evaluation parameters } \\
\hline & $\begin{array}{l}\text { Thickness }(\mathrm{mm}) \\
(n=3) \text { Mean } \pm \mathrm{SD}\end{array}$ & $\begin{array}{l}\text { Hardness }(\mathrm{kg} / \mathrm{cm}) \\
(n=3) \text { Mean } \pm \mathrm{SD}\end{array}$ & $\begin{array}{l}\text { Weight variation }(\mathrm{mg}) \\
(n=20) \text { Mean } \pm \mathrm{SD}\end{array}$ & $\begin{array}{c}\text { Friability }(\%) \\
(n=10) \text { Mean } \pm \text { SD }\end{array}$ & $\begin{array}{l}\text { Drug content }(\%) \\
(n=3) \text { Mean } \pm \text { SD }\end{array}$ \\
\hline F1 & $3.36 \pm 0.08$ & $12 \pm 0.08$ & $300.45 \pm 1.03$ & $0.11 \pm 0.02$ & $98 \pm 0.88$ \\
\hline $\mathrm{F} 2$ & $3.33 \pm 0.02$ & $10 \pm 0.05$ & $294.66 \pm 0.07$ & $0.49 \pm 0.03$ & $101 \pm 0.98$ \\
\hline F3 & $3.76 \pm 0.06$ & $8 \pm 0.07$ & $310.66 \pm 0.03$ & $0.58 \pm 0.05$ & $99.45 \pm 1.45$ \\
\hline $\mathrm{F} 4$ & $3.56 \pm 0.08$ & $8 \pm 0.10$ & $302.33 \pm 0.04$ & $0.17 \pm 0.04$ & $97.33 \pm 0.07$ \\
\hline F5 & $3.22 \pm 0.05$ & $12 \pm 0.05$ & $305.33 \pm 0.06$ & $0.478 \pm 0.10$ & $101 \pm 0.96$ \\
\hline F6 & $3.54 \pm 0.04$ & $12 \pm 0.07$ & $298.63 \pm 0.05$ & $0.17 \pm 0.03$ & $99.7 \pm 1.44$ \\
\hline F7 & $3.78 \pm 0.08$ & $12 \pm 0.06$ & $311.66 \pm 0.10$ & $0.166 \pm 0.02$ & $98.32 \pm 1.27$ \\
\hline F8 & $3.2 \pm 0.03$ & $12 \pm 0.10$ & $307.66 \pm 0.04$ & $0.289 \pm 0.05$ & $99.2 \pm 0.87$ \\
\hline F9 & $3.6 \pm 0.07$ & $12 \pm 0.11$ & $291.33 \pm 0.08$ & $0.176 \pm 0.02$ & $102.3 \pm 0.69$ \\
\hline F10 & $3.4 \pm 0.05$ & $12 \pm 0.04$ & $303.66 \pm 0.10$ & $0.16 \pm 0.01$ & $99 \pm 0.45$ \\
\hline F11 & $3.22 \pm 0.06$ & $12 \pm 0.05$ & $297.66 \pm 0.24$ & $0.162 \pm 0.03$ & $97 \pm 0.95$ \\
\hline F12 & $3.6 \pm 0.04$ & $12 \pm 0.07$ & $311.66 \pm 0.03$ & $0.152 \pm 0.05$ & $101 \pm 0.23$ \\
\hline F13 & $3.5 \pm 0.03$ & $10 \pm 0.10$ & $306.66 \pm 0.02$ & $0.127 \pm 0.05$ & $101 \pm 0.66$ \\
\hline F14 & $3.5 \pm 0.09$ & $10 \pm 0.03$ & $309.66 \pm 0.10$ & $0.133 \pm 0.06$ & $99 \pm 0.78$ \\
\hline F15 & $3.45 \pm 0.10$ & $10 \pm 0.07$ & $301.66 \pm 0.06$ & $0.117 \pm 0.05$ & $97.56 \pm 0.98$ \\
\hline F16 & $3.56 \pm 0.11$ & $10 \pm 0.05$ & $299.33 \pm 0.08$ & $0.124 \pm 0.07$ & $103 \pm 0.95$ \\
\hline F17 & $3.88 \pm 0.03$ & $10 \pm 0.03$ & $312.12 \pm 0.06$ & $0.323 \pm 0.04$ & $99.12 \pm 1.02$ \\
\hline F18 & $3.45 \pm 0.02$ & $10 \pm 0.07$ & $290.12 \pm 0.03$ & $0.45 \pm 0.05$ & $102 \pm 0.05$ \\
\hline
\end{tabular}

Effects of various ingredients and their concentration on drug release were studied. Formulations F1 and F2 showed release of $87.17 \%$ and $78.22 \%$ at end of 4 th hr, respectively. While F3 and F4 showed release of $66.81 \%$ and $44.58 \%$ at the end of 4 th hr, respectively, indicating sustained effect due to higher concentration of HCSO.
Batches formulated with HPMC K4M showed decrease in $\%$ drug release with increase in polymer concentration. Formulation F6 showed release of $97.13 \%$ at end of 12 th hr, while F7 and F8 exhibited higher retardation.

High viscosity grade HPMC contents results in a greater amount of gel being formed. This gel increases diffusion path 
TABLE 4: Floating lag time and total floating time of designed formulations (F1-F18).

\begin{tabular}{lccc}
\hline S. No & $\begin{array}{c}\text { Formulation } \\
\text { code }\end{array}$ & $\begin{array}{c}\text { Floating lag } \\
\text { time (min:sec) }\end{array}$ & $\begin{array}{c}\text { Total floating } \\
\text { time (hrs) }\end{array}$ \\
\hline 1 & F1 & $3: 01$ & $>12$ \\
2 & F2 & $2: 41$ & $>12$ \\
3 & F3 & $2: 19$ & $>12$ \\
4 & F4 & $2: 12$ & $>12$ \\
5 & F5 & $2: 06$ & $>12$ \\
6 & F6 & $1: 60$ & $>12$ \\
7 & F7 & $1: 53$ & $>12$ \\
8 & F8 & $1: 40$ & $>12$ \\
9 & F9 & $1: 20$ & $>12$ \\
10 & F10 & $1: 15$ & $>12$ \\
11 & F11 & $1: 18$ & $>12$ \\
12 & F12 & $1: 10$ & $>12$ \\
13 & F15 & $1: 17$ & $>12$ \\
14 & F16 & $1: 06$ & $>12$ \\
15 & F17 & $1: 09$ & $>12$ \\
16 & F18 & $1: 02$ & $>12$ \\
\hline
\end{tabular}

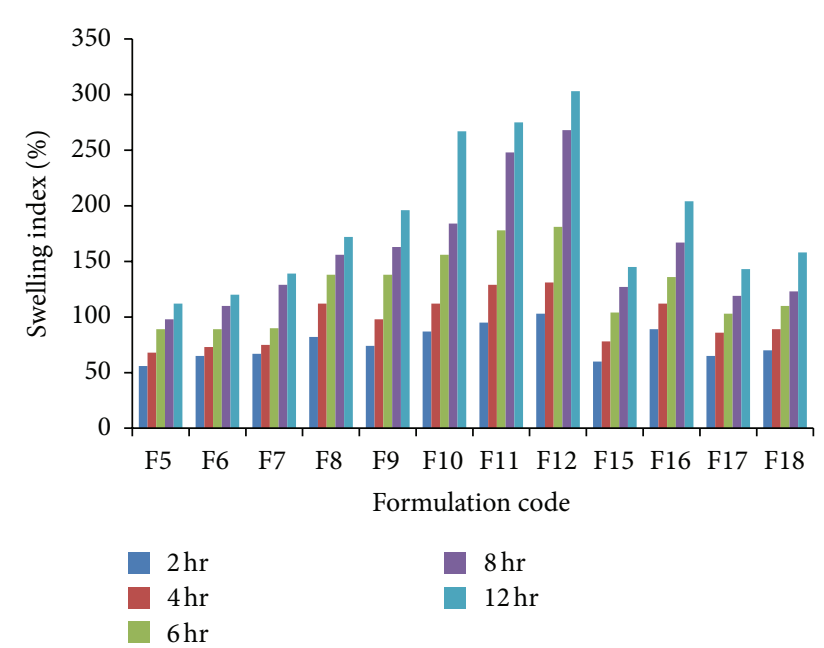

FIGURE 7: Swelling index of gastroretentive floating tablets of Atenolol.

length of the drug. Its viscous nature also affects the diffusion coefficient of the drug.

As a result reduction in drug release is obtained. Batches formulated with HPMC K15M and HPMC K4M showed similar release pattern till 4 th $\mathrm{hr}$. After 4 th $\mathrm{hr}$, release was retarded with formulations containing HPMC K15M to higher extent because of its high viscosity as compared to HPMC K4M. Thus, all HPMC K15M formulations exhibited sustained effect for more than $12 \mathrm{hrs}$.

It was observed that the type of polymer/retardant influences the drug release pattern. HCSO showed release of drug by erosion mechanism, while HPMC by diffusion mechanism. It was observed that as the concentration of

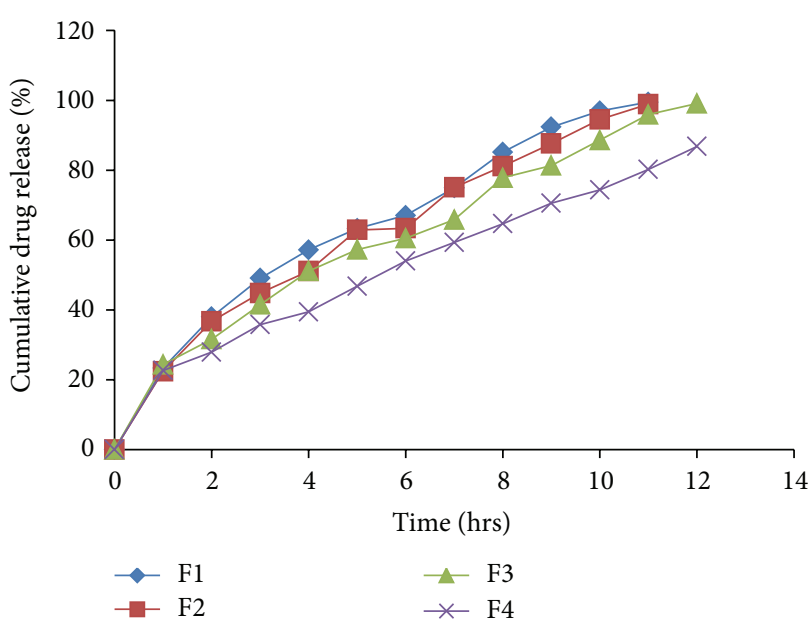

FIGURE 8: In vitro drug released profile of formulations F1 to F4.

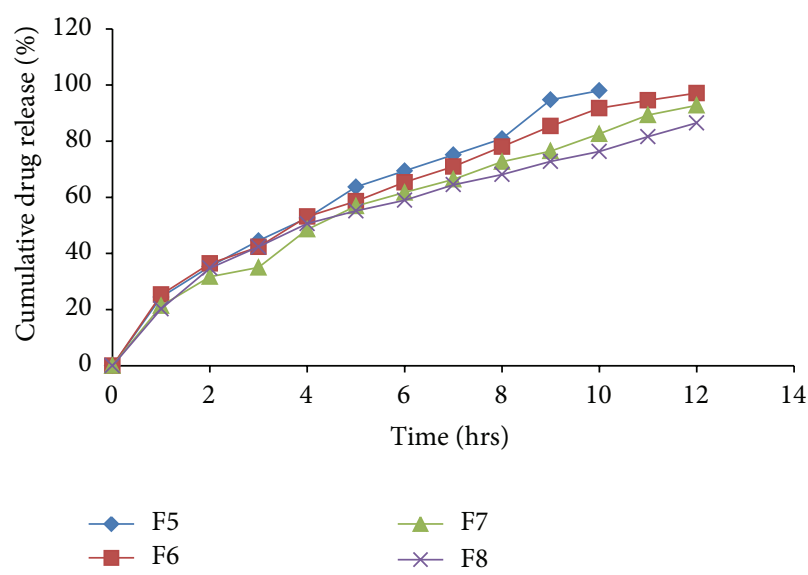

FIGURE 9: In vitro drug released profile of formulations F5 to F8.

polymer/retardant increased in formulations, the \% drug release was decreased. Formulations F13 and F14 busted in $1 \mathrm{hr}$ due to failure of matrix to entrap gas.

Formulation F15 with HCSO, HPMC K4M, and HPMC $\mathrm{K} 15 \mathrm{M}$ in ratio $2: 1: 1$ showed release of $57.2 \%$ at end of 4 th $\mathrm{hr}$. While F16 with HCSO, HPMC K4M, and HPMC K15M in ratio $1: 2: 1$ showed release of $51.13 \%$, but complete drug release occurred at 11th hr. Formulation F17 was considered as optimized formulation because it showed $51.08 \%$ drug release at end of $4 \mathrm{th} \mathrm{hr}$ and successful sustained effect up to $12 \mathrm{hrs}$. Formulation F18 with higher amount of hydrophilic polymers, HPMC K4M and HPMC K15M showed release more than $12 \mathrm{hrs}$. Thus, the optimum combination of hydrophilichydrophobic matrix forming material required in formulation to get buoyancy and release of drug over $12 \mathrm{hrs}$.

3.7. Curve Fitting Analysis. The data obtained from in vitro dissolution studies were fitted to zero-order, first-order, Higuchi, and Korsemeyer-Peppas equations. The dissolution data obtained were plotted as time versus cumulative percent drug released as zero order, time versus log cumulative 
TABLE 5: Swelling Index of gastroretentive floating tablets of Atenolol.

\begin{tabular}{|c|c|c|c|c|c|c|}
\hline \multirow{2}{*}{ S. No } & \multirow{2}{*}{ Formulation code } & \multicolumn{5}{|c|}{ Swelling index (\%) at different time interval } \\
\hline & & $2 \mathrm{hr}$ & $4 \mathrm{hr}$ & $6 \mathrm{hr}$ & $8 \mathrm{hr}$ & $12 \mathrm{hr}$ \\
\hline 1 & F5 & 56 & 68 & 89 & 98 & 112 \\
\hline 2 & F6 & 65 & 73 & 89 & 110 & 120 \\
\hline 3 & F7 & 67 & 75 & 90 & 129 & 139 \\
\hline 4 & F8 & 82 & 112 & 138 & 156 & 172 \\
\hline 5 & F9 & 74 & 98 & 138 & 163 & 196 \\
\hline 6 & F10 & 87 & 112 & 156 & 184 & 267 \\
\hline 7 & F11 & 95 & 129 & 178 & 248 & 275 \\
\hline 8 & F12 & 103 & 131 & 181 & 268 & 303 \\
\hline 9 & F15 & 60 & 78 & 104 & 127 & 145 \\
\hline 10 & F16 & 89 & 112 & 136 & 167 & 204 \\
\hline 11 & F17 & 65 & 86 & 103 & 119 & 143 \\
\hline 12 & F18 & 70 & 89 & 110 & 123 & 158 \\
\hline
\end{tabular}

TABLE 6: The in vitro drug release profiles for the formulations (F1-F8).

\begin{tabular}{lcccccccc}
\hline Time (hrs) & F1 & F2 & F3 & F4 & F5 & F6 & F7 & F8 \\
\hline 0 & 0 & 0 & 0 & 0 & 0 & 0 & 0 \\
1 & $27.92 \pm 0.65$ & $30.23 \pm 0.45$ & $24.45 \pm 0.90$ & $21.34 \pm 0.84$ & $24.44 \pm 0.55$ & $25.34 \pm 0.56$ & $21.33 \pm 0.78$ & $20.22 \pm 0.60$ \\
2 & $73.9 \pm 0.77$ & $55.65 \pm 0.60$ & $33.21 \pm 0.67$ & $29.35 \pm 0.67$ & $35.31 \pm 1.45$ & $36.42 \pm 1.34$ & $31.7 \pm 0.60$ & $34.75 \pm 0.78$ \\
3 & $83.46 \pm 0.77$ & $72.05 \pm 0.34$ & $41.17 \pm 0.45$ & $34.65 \pm 0.57$ & $44.54 \pm 0.60$ & $42.3 \pm 0.45$ & $35.01 \pm 0.66$ & $42.37 \pm 0.66$ \\
4 & $87.17 \pm 0.25$ & $78.22 \pm 0.67$ & $55.15 \pm 0.55$ & $38.12 \pm 0.34$ & $52.62 \pm 0.78$ & $53.12 \pm 1.45$ & $48.56 \pm 1.45$ & $50.63 \pm 0.45$ \\
5 & $89.89 \pm 0.95$ & $83.29 \pm 0.56$ & $61.91 \pm 0.56$ & $40.76 \pm 0.88$ & $63.71 \pm 0.33$ & $58.63 \pm 0.56$ & $56.86 \pm 0.48$ & $55.16 \pm 0.55$ \\
6 & $90.96 \pm 0.46$ & $86.61 \pm 0.89$ & $66.81 \pm 0.45$ & $44.58 \pm 0.33$ & $69.41 \pm 0.89$ & $65.36 \pm 0.88$ & $61.72 \pm 0.34$ & $58.94 \pm 0.95$ \\
7 & $93.08 \pm 0.60$ & $90.21 \pm 1.23$ & $71.67 \pm 0.88$ & $48.82 \pm 0.45$ & $75.13 \pm 0.55$ & $70.93 \pm 0.60$ & $66.39 \pm 0.56$ & $64.46 \pm 0.88$ \\
8 & $94.29 \pm 0.34$ & $92.16 \pm 0.56$ & $74.56 \pm 0.25$ & $51.44 \pm 0.77$ & $80.87 \pm 0.45$ & $78.03 \pm 0.34$ & $72.66 \pm 0.66$ & $68.12 \pm 0.93$ \\
9 & $99.06 \pm 0.45$ & $94.61 \pm 0.60$ & $76.09 \pm 0.89$ & $56.09 \pm 0.23$ & $94.77 \pm 0.23$ & $85.36 \pm 0.33$ & $76.46 \pm 0.90$ & $72.8 \pm 0.67$ \\
10 & - & $96.54 \pm 0.23$ & $80.28 \pm 0.24$ & $61.43 \pm 1.33$ & $98.01 \pm 0.34$ & $91.73 \pm 0.56$ & $82.62 \pm 0.55$ & $76.34 \pm 0.34$ \\
11 & - & $98.69 \pm 0.45$ & $83.4 \pm 1.23$ & $65.08 \pm 0.33$ & - & $94.55 \pm 0.99$ & $89.33 \pm 0.78$ & $81.6 \pm 0.66$ \\
12 & - & - & - & $71.23 \pm 0.45$ & - & $97.13 \pm 1.24$ & $92.75 \pm 0.88$ & $86.49 \pm 0.45$ \\
\hline
\end{tabular}

${ }^{*}$ All above reading are average $\pm \mathrm{SD}, n=6$.

TABLE 7: The in vitro drug release profiles for the formulations (F9-F18).

\begin{tabular}{lcccccccc}
\hline Time $(\mathrm{hrs})$ & F9 & F10 & F11 & F12 & F15 & F16 & F17 & F18 \\
\hline 0 & 0 & 0 & 0 & 0 & 0 & 0 & 0 \\
1 & $26.34 \pm 0.78$ & $23.34 \pm 0.96$ & $22.35 \pm 0.98$ & $22.78 \pm 0.99$ & $23.34 \pm 0.78$ & $22.45 \pm 0.90$ & $24.34 \pm 0.67$ & $22.66 \pm 0.88$ \\
2 & $34.27 \pm 1.25$ & $36.23 \pm 0.67$ & $33.71 \pm 0.78$ & $31.41 \pm 0.78$ & $38 \pm 0.46$ & $36.74 \pm 0.67$ & $31.56 \pm 0.54$ & $27.89 \pm 0.97$ \\
3 & $42.59 \pm 0.90$ & $42.19 \pm 0.89$ & $36.72 \pm 1.02$ & $35.8 \pm 0.60$ & $49.04 \pm 0.78$ & $44.82 \pm 0.78$ & $41.51 \pm 0.78$ & $35.81 \pm 0.67$ \\
4 & $51.04 \pm 0.56$ & $50.83 \pm 0.67$ & $43.53 \pm 0.67$ & $43.31 \pm 0.66$ & $57.2 \pm 0.98$ & $51.13 \pm 0.65$ & $51.08 \pm 1.34$ & $39.45 \pm 0.45$ \\
5 & $56.6 \pm 0.89$ & $58.22 \pm 0.78$ & $46.29 \pm 0.69$ & $45.39 \pm 0.56$ & $63.3 \pm 0.67$ & $62.9 \pm 0.67$ & $57.29 \pm 1.55$ & $46.78 \pm 0.33$ \\
6 & $63.82 \pm 1.33$ & $63.37 \pm 1.23$ & $49 \pm 0.77$ & $47.44 \pm 0.88$ & $67.06 \pm 0.56$ & $63.36 \pm 0.55$ & $60.5 \pm 0.78$ & $53.98 \pm 0.78$ \\
7 & $67.44 \pm 0.56$ & $64.8 \pm 0.78$ & $51.58 \pm 0.66$ & $53.18 \pm 0.73$ & $74.96 \pm 0.77$ & $75.08 \pm 0.77$ & $65.83 \pm 0.56$ & $59.34 \pm 0.66$ \\
8 & $70.89 \pm 0.34$ & $66.99 \pm 1.45$ & $56.52 \pm 0.45$ & $55.55 \pm 0.67$ & $85.18 \pm 0.55$ & $81.15 \pm 0.44$ & $77.82 \pm 0.55$ & $64.67 \pm 0.34$ \\
9 & $76.38 \pm 0.45$ & $72.58 \pm 0.78$ & $61.84 \pm 0.79$ & $59.05 \pm 1.67$ & $92.36 \pm 0.78$ & $87.63 \pm 0.78$ & $81.32 \pm 0.88$ & $70.56 \pm 0.78$ \\
10 & $81.49 \pm 0.68$ & $79.16 \pm 0.60$ & $68.24 \pm 0.66$ & $62.97 \pm 0.78$ & $96.94 \pm 0.55$ & $94.53 \pm 0.87$ & $88.61 \pm 0.98$ & $74.33 \pm 0.67$ \\
11 & $86.5 \pm 0.56$ & $82.82 \pm 0.78$ & $72.31 \pm 0.56$ & $69.58 \pm 0.23$ & $99.49 \pm 0.67$ & $98.91 \pm 0.98$ & $95.95 \pm 1.56$ & $80.22 \pm 0.65$ \\
12 & $93.96 \pm 0.95$ & $85.57 \pm 0.85$ & $76.59 \pm 0.77$ & $72.18 \pm 0.56$ & - & - & $99.08 \pm 0.88$ & $86.78 \pm 0.73$ \\
\hline
\end{tabular}

\footnotetext{
${ }^{*}$ All above reading are average $\pm \mathrm{SD}, n=6$.
} 
TABLE 8: Release kinetics data of the Formulations F1-F18.

\begin{tabular}{|c|c|c|c|c|c|c|}
\hline \multirow{2}{*}{ S. No } & \multirow{2}{*}{ Formulation code } & \multirow{2}{*}{$\begin{array}{c}\text { Zero order } \\
R^{2}\end{array}$} & \multirow{2}{*}{$\begin{array}{c}\text { First order } \\
\qquad R^{2}\end{array}$} & \multirow{2}{*}{$\begin{array}{c}\text { Higuchi } \\
R^{2}\end{array}$} & \multicolumn{2}{|c|}{ Korsmeyer-Peppas } \\
\hline & & & & & $n$ & $R^{2}$ \\
\hline 1 & $\mathrm{~F} 1$ & 0.6088 & 0.859 & 0.725 & 0.473 & 0.746 \\
\hline 2 & $\mathrm{~F} 2$ & 0.774 & 0.988 & 0.8811 & 0.466 & 0.882 \\
\hline 3 & F3 & 0.96 & 0.987 & 0.974 & 0.488 & 0.96 \\
\hline 4 & $\mathrm{~F} 4$ & 0.992 & 0.956 & 0.949 & 0.389 & 0.925 \\
\hline 5 & F5 & 0.988 & 876 & 0.992 & 0.554 & 0.988 \\
\hline 6 & F6 & 0.988 & 0.917 & 0.99 & 0.532 & 0.988 \\
\hline 7 & F7 & 0.985 & 0.937 & 0.979 & 0.533 & 0.958 \\
\hline 8 & F8 & 0.985 & 0.972 & 0.995 & 0.462 & 0.993 \\
\hline 9 & F9 & 0.988 & 0.905 & 0.991 & 0.497 & 0.989 \\
\hline 10 & F10 & 0.972 & 0.977 & 0.991 & 0.459 & 0.992 \\
\hline 11 & F11 & 0.991 & 0.955 & 0.992 & 0.407 & 0.955 \\
\hline 12 & F12 & 0.991 & 0.974 & 0.974 & 0.396 & 0.961 \\
\hline 13 & F15 & 0.986 & 0.803 & 0.99 & 0.543 & 0.993 \\
\hline 14 & F16 & 0.992 & 0.806 & 0.984 & 0.545 & 0.9885 \\
\hline 15 & F17 & 0.992 & 0.857 & 0.978 & 0.549 & 0.971 \\
\hline 16 & F18 & 0.998 & 0.867 & 0.977 & 0.543 & 0.9734 \\
\hline
\end{tabular}

TABLE 9: Stability study of formulation F17.

\begin{tabular}{lcccc}
\hline \multirow{2}{*}{ Time (months) } & \multirow{2}{*}{ Drug content (\%) } & \multicolumn{2}{c}{ Floating behavior } & In vitro drug release at 12th hr \\
\hline Zero & & FLT (min:sec) & Total floating time (hrs) & 99.08 \\
First & 98.07 & $1: 06$ & $>12$ & 99.04 \\
Second & 98.09 & $1: 05$ & $>12$ & 99.12 \\
Third & 99.0 & $1: 06$ & $>12$ & 98.76 \\
\hline
\end{tabular}

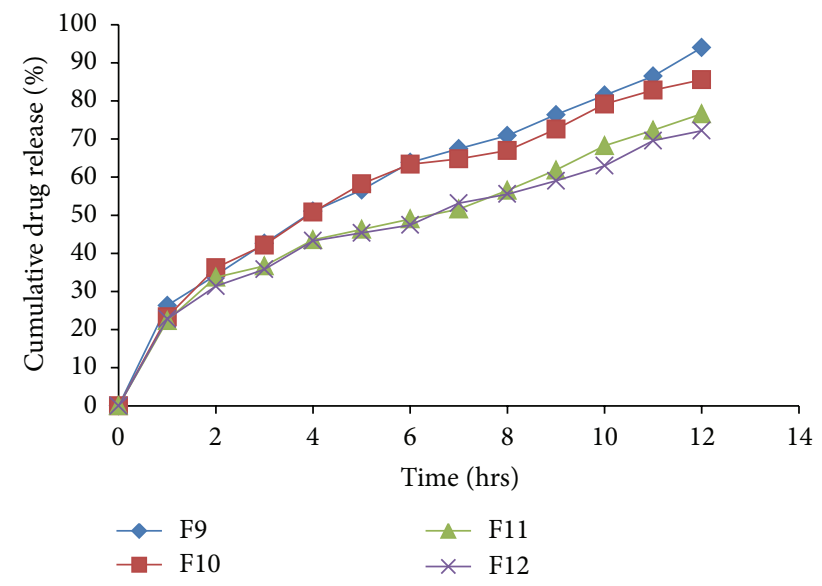

FIGURE 10: In vitro drug released profile of formulations F9 to F12.

percent drug remaining as First order release kinetics, square root of time versus cumulative percent drug released as Higuchi equation, and log time versus log cumulative percent drug released as per Korsemeyer-Peppas equation. The best fit with the highest determination $R^{2}$ coefficients was shown by both Peppas and zero order model followed by Higuchi

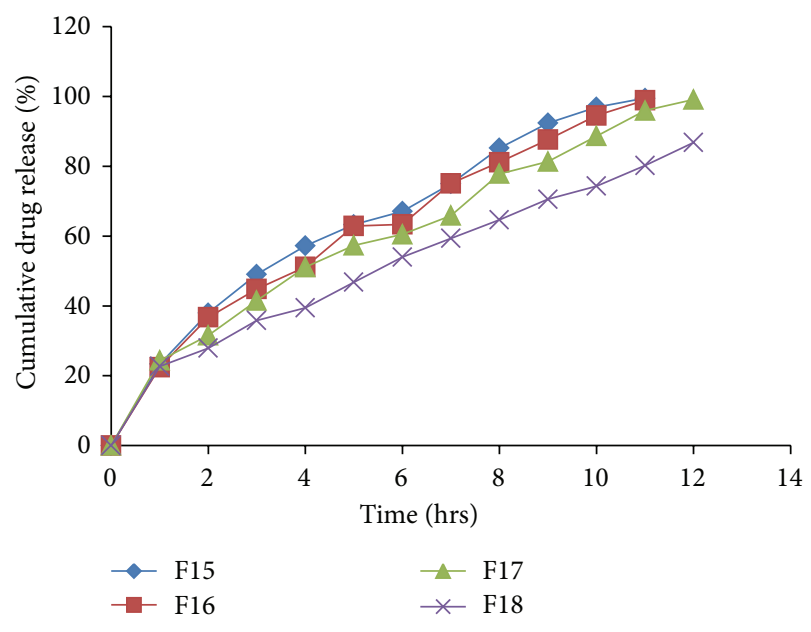

FIGURE 11: In vitro drug released profile of formulations F15 to F18.

model which indicate the drug release via diffusion mechanism. Zero-order rate equation, which describes the system where release rate is independent of the concentration of the dissolved species. The Korsemeyer-peppas equation is used to analyze the release of pharmaceutical polymeric dosage forms, when the release mechanism is not well known or 
when more than one type of release phenomena could be involved. The values of $n$ with regression coefficient of all the formulations are shown in Table 8. The value of $n$ obtained was in the range of 0.519 to 0.765 , indicating nonfickian diffusion in case of tablets formulated with HPMC K4M only. While tablets of hydrogenated cotton seed oil and HPMC K15M followed fickian diffusion, matrix tablet of HPMC and hydrogenated cottonseed oil followed nonfickian diffusion. From the results, it was confirmed that all the formulations are following zero order models followed by higuchi model which indicate the drug release via diffusion mechanism. Formulation F17 gave 99.08\% drug release at 12th hr fulfilling the aim of study and, hence, was selected as optimized batch.

3.8. Stability Studies. The results of stability studies did not show any significant change in the physical appearance, drug content, in vitro buoyancy studies, and in vitro dissolution studies of above four formulations as shown in Table 9.

\section{Conclusion}

The results of the present research work demonstrates that the combination of both hydrophilic and hydrophobic polymers successfully employed for formulating the sustained release matrix tablets of Atenolol. It is observed that optimum concentration of each of the polymer in combination was able to produce desired formulation which releases complete drug in 12 hours. The mechanism of drug release has observed the combined effect of diffusion and erosion for sustained drug release. So, the combination of both hydrophilic and hydrophobic retardant was suitable to produce the matrix tablet rather than using a single type of polymer. The present study also revealed that HCSO can be used as a matrixforming agent for the preparation of floating tablets. Using $\mathrm{HCSO}$ also makes the formulation cost effective.

\section{References}

[1] S. Shahi, A. Sonawane, S. Vanamore, and N. Zadbuke, "Formulation and in-vitro characterization of acyclovir floating matrix tablets: a factorial design study," Journal of Applied Pharmaceutical Science, vol. 3, no. 5, p. 65, 2013.

[2] A. Yadav and D. Jain, "Formulation development and characterization of gastroretentive floating beads," Asian Journal of Pharmacy and Medical Science, vol. 2, no. 1, pp. 1-10, 2012.

[3] B. S. Sudha, B. K. Sridhar, and A. Srinatha, "Modulation of tramadol release from a hydrophobic matrix: implications of formulations and processing variables," AAPS PharmSciTech, vol. 11, no. 1, pp. 433-440, 2010.

[4] V. T. Yadav, B. D. Jayswal, K. N. Patel, B. A. Patel, and P. A. Patel, "Formulation and evaluation of floating tablet of amoxicillin trihydrate," International Journal For Pharmaceutical Research Scholars, vol. 1, no. 2, pp. 307-309, 2012.

[5] J. Padmavathy, D. Saravanan, and D. Rajesh, "Formulation and evaluation of Ofloxacin floating tablets using HPMC," International Journal of Pharmacy and Pharmaceutical Sciences, vol. 3, no. 1, pp. 170-173, 2011.

[6] B. Brahmaiah, G. P. Bhagath, and M. Gudipati, "Formulation and evaluation of gastroretentive floating drug delivery system of metoprolol tartarate," International Journal of Life Sciences Biotechnology and Pharma Research, vol. 2, no. 1, pp. 183-197, 2013.

[7] N. Singh, A. Bose, R. Mishra, V. Jain, S. Dhakar, and D. Bharati, "Development and evaluation of gastroretentive floating drug delivery system for tizanidine hydrochloride and its in-vivo gamma-scintigraphic studies using tc-99m tracer," Asian Journal of Pharmaceutical and Clinical Research, vol. 5, no. 3, p. 57, 2012.

[8] M. Varma and S. Vijaya, "Development and evaluation of gastroretentive floatingdrug delivery system of atenolol," International Journal of Pharmaceutical and Chemical Sciences, vol. 1, no. 2, p. 869, 2012.

[9] S. Chander, K. Shireesh, and B. Nagendra, "Preparation and evaluation of gastro retentive floating tablets of ketoconazole," International Journal of Pharma Research and Development, vol. 2, no. 9, pp. 175-176, 2010.

[10] R. P. Tayade, V. M. Thakare, B. W. Tekade, and V. R. Patil, "Formulation and evaluationof captopril floating matrix tablet," International Journal of Pharmaceutical Research and Development, vol. 4, no. 6, p. 116, 2012.

[11] G. Eswer and M. Saritha, "Formulation and evaluation of atenolol floating tablets using different polymers: guargum, sodium alginate, Hpmc100cps and Carbopol940," International Journal of Pharmaceutical \& Biological Archives, vol. 2, no. 4, p. 1148, 2011.

[12] S. Singh, K. Prajapati, A. K. Pathak, and A. Mishra, "Formulation and evaluation of floating tablet of Captopril," International Journal of PharmTech Research, vol. 3, no. 1, pp. 333-341, 2011.

[13] P. N. Kendre, S. N. Lateef, R. K. Godge, P. D. Chaudhari, S. L. Fernandes, and S. K. Vibhute, "Oral sustained delivery of theophylline floating matrix tablets- formulation and in-vitro evaluation," International Journal of PharmTech Research, vol. 2, no. 1, pp. 130-139, 2010. 

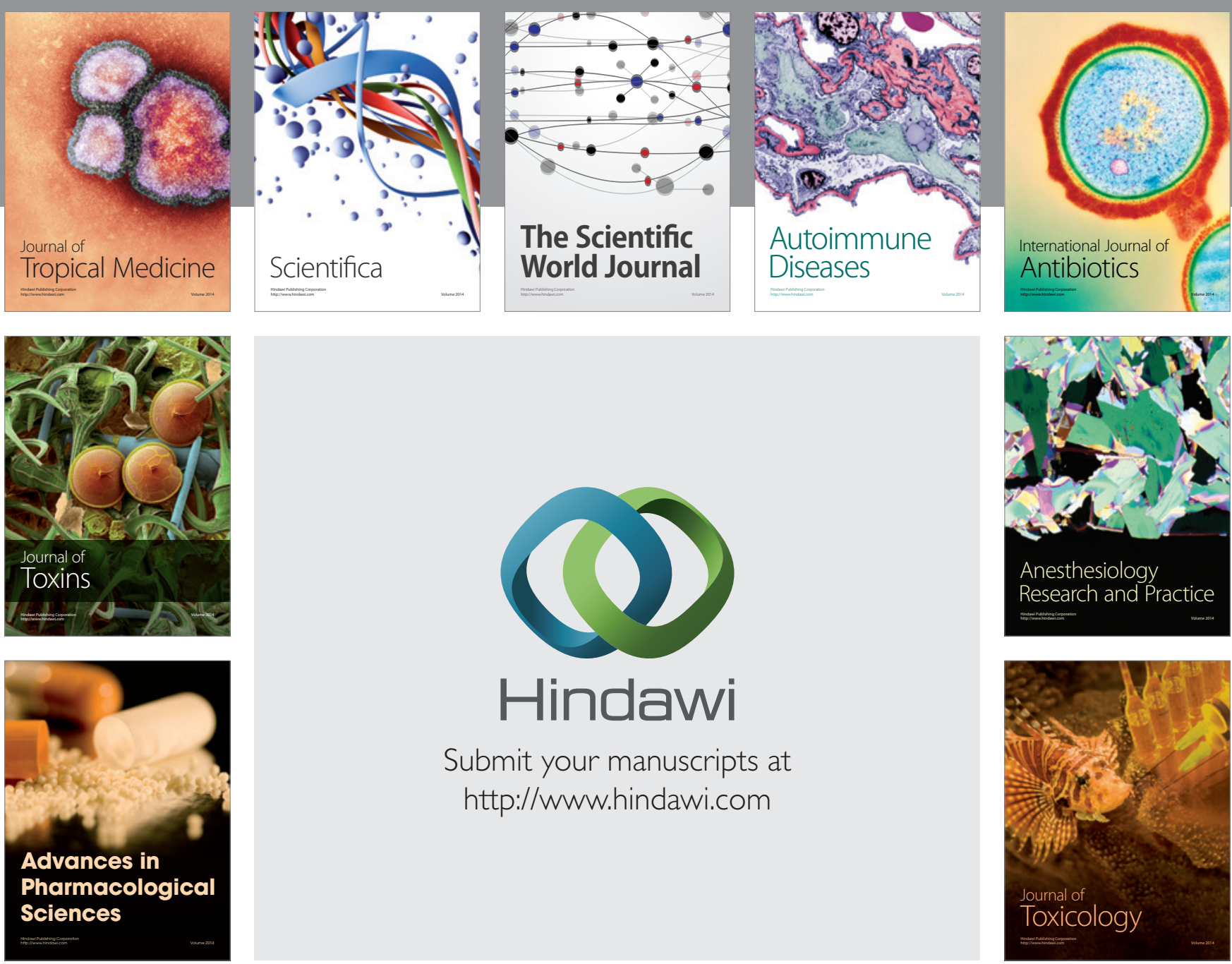

\section{Hindawi}

Submit your manuscripts at

http://www.hindawi.com
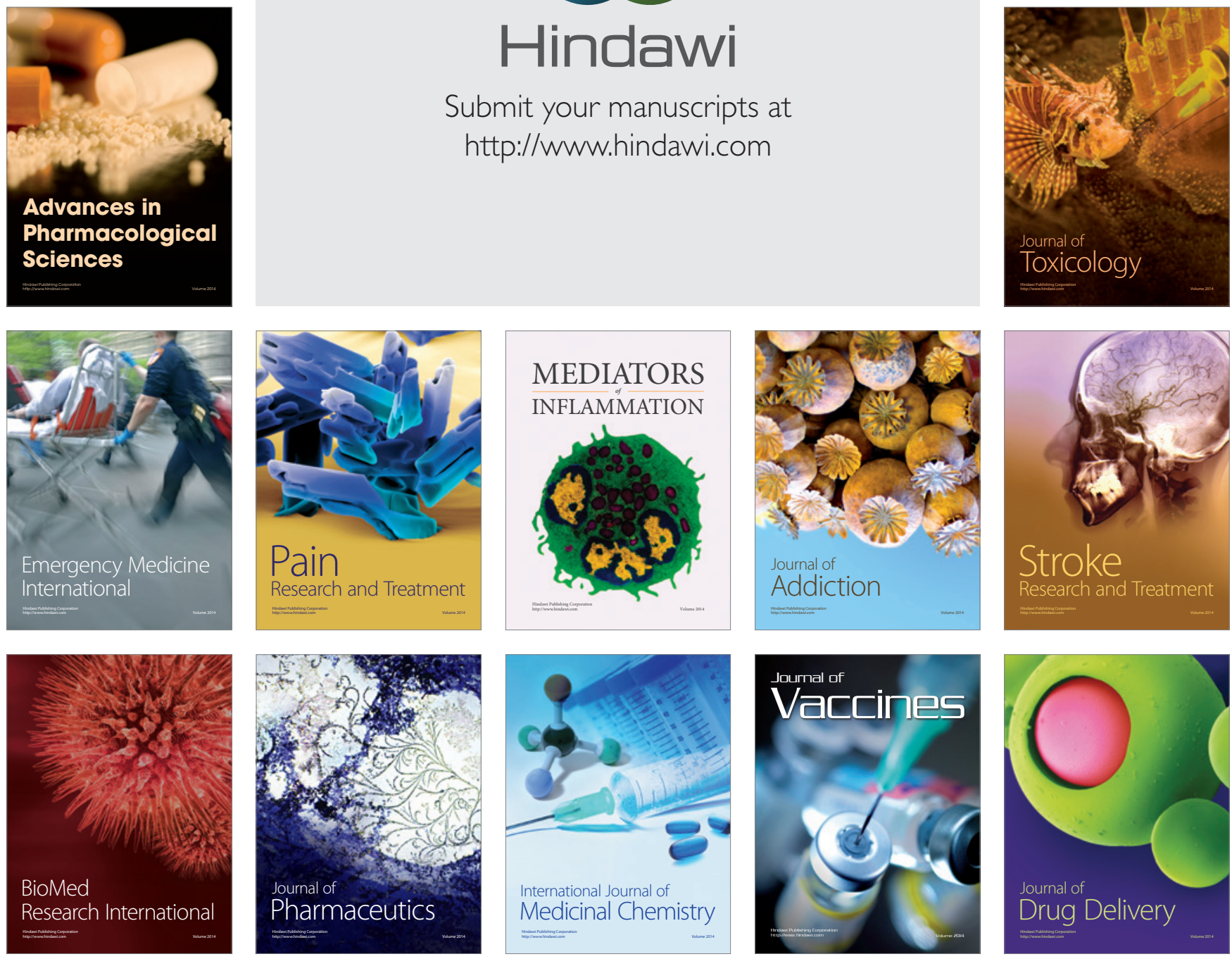